\title{
The Role of Nanoparticles for Enhancing Enzymes Activity to Remove Stains from Paper manuscripts and Leather Artifacts: Article Review
}

\section{Mahmoud Abdel-Nasser', Gomaa Abdel-Maksoud ${ }^{2}$, Sawsan S. Darwish ${ }^{2}$, Mohamed S. Abdel-Aziz ${ }^{3}$}

\begin{abstract}
:
There are many paper manuscripts and leather artifacts in different locations in Egypt (museums, libraries and etc.). Some of these locations are in improper conditions. According to that, some stains derived from different sources can be found on the surface of these materials. These stains are considered one of the most important problems that façade the conservators. In archaeological field, enzymes are used alone for removing stains. The aim of this paper is to focus on the role of some nanoparticles to enhance the activity of enzymes for removing stains more than being used alone. This study concludes that the use of nanoparticles with enzymes have high stability in a wide range of temperature and $\mathrm{pH}$, compared to free enzymes. They benefit from the properties of nanoparticles such as size, shape, structure and their high catalysis capacity biocatalysts enzymes.
\end{abstract}

${ }^{1}$ Department of Manuscript Conservation, Al-Azhar Al-Sharif Library, Cairo, Egypt.

${ }^{2}$ Conservation Department, Faculty of Archaeology, Cairo University, Giza, Egypt.

${ }^{3}$ Microbial Chemistry Department, National Research Centre, 33 El Bohouth St, Dokki, Giza, P.O. 12622, Egypt. 
Keywords: Enzymes, nanoparticles, stains, synthesize, biocatalysis, photo catalyst, cofactor.

\section{Introduction}

Stains are considered as a deterioration aspect to archaeological materials, where they lead to discoloration and distortion of their surfaces. The seriousness of the stains lies not only in the appearance of the distorted surface, but also in formation of different damage aspects such as high acidity due to rust spots as well as biological stains. There are many stains on paper manuscripts and leather artifacts because of their organic nature and properties (Timar-Balazsy \& Eastop, 1998; Khattab, 2002).

Enzymes are specialized proteins produced by living cells to stimulate different chemical reactions. They have the same properties of proteins, which are affected by heat, acids and strong bases, that caused to break down and change their natural properties and stop the activity (France, 2000; Pedro, 2003; Rakesh, 2012). Some enzymes need additional chemicals that are needed by the enzyme for its effectiveness. These substances are called co-factors, which are non-protein substances. They are linked to certain enzymes and are required for the activity of these enzymes. The co-factors added to the enzymes consist of metals or organic molecules derived from vitamins called Co-enzymes (Holum, 1986; Berg, 2002; cui \& karpluus, 2003).

Recently with the development of Nanotechnology, metals have been used as co-factors to improve the properties and catalysis of enzymes activity in the form of nanoscale. 
Nanoparticles of catalytic material provide the benefit of increased surface area which allows for an increased reaction rate (Tandon \& Singh, 2014). When well dispersed, the Nano particulate catalyst forms a stable suspension in the reaction medium allowing an elevated rate of reaction. In addition, nanoparticles can permit additional catalytic functionalities due to their unique properties, for example titanium nanoparticles exhibit photo oxidation on their surfaces and photo catalyst that led to self-cleaning of surfaces (Yan, et al., 2014). Other nanoparticles can utilize light energy as a result of their photo physical properties.

Also when nanoparticles are mixed with enzyme, the solubility of the enzyme in organic solvents increases instead of aqueous media and give numerous advantages to enzymatic reactions such as: increased solubility of hydrophobic substrates or suppression of water-dependent side reactions. However, the melting point of the enzyme in organic solvents requires many studies to investigate its role (Sandro, et al., 2015). The aim of the present paper is to display removal method for the stained paper manuscripts and leather artifacts by using enzyme with addition nanoparticles catalytic to improve the efficiency of enzymes for application in the restoration field, especially in the restoration of paper manuscripts and leather artifacts.

\section{Formation of Stains on Paper Manuscripts and Leather Artifacts}

Many of the stains are formed on paper manuscripts and leather artifacts according to the different sources, form and a potential 
effect on organic materials (Jain, 2003; Cybulska \& Maik, 2007).

\subsection{Most Common Stains are found in Paper Manuscripts and Leather Artifacts}

\subsubsection{Rust stains}

Rust stains are shown in the organic materials through the presence of organic materials with minerals in the middle of one with the availability of wet conditions and moisture, which gives the opportunity to deposit rust products on the surface of the metal (Ibrahim, 2014).

\subsubsection{Stains arising from the activity of microorganisms}

Precise living organisms cause biological damage, which includes staining, mildew, and change in the physical properties of the material. This leads to the appearance of stains resulting from pigments produced by the fungus, which lead to the distortion of the material (Nitterus, 2000).

\subsubsection{Dust and mud stains}

Dust and mud stains are either dry which removed easily or mixed with water and oil. This leads to the difficulty of disposal because of the overlap and links between them and the fibers. In addition, they contain insect eggs, fungi or bacteria. They are also mixed with other materials such as sand, causing mechanical damage to the fibers( Abdel Kareem, 2010).

\subsubsection{Adhesives stains}

This type of stains affects the mechanical properties of archaeological materials and accelerates the process of damage in general. In addition, adhesives such as glue and starch increase the susceptibility and dryness of substances in the dry 
atmosphere and help the growth of fungi in the wet atmosphere (Abdel Kareem, 2010).

\subsubsection{Fats, oils and other greasy materials}

These materials act as an adhesion or bonding tool to the granules of the damaged materials with the center of the fibers. They also act as a packaging tool for other types of deterioration aspects. In addition, they contain free acids. Oil creams containing polyunsaturated bonds can be oxidized and form many hard stains "as a network" (Khattab, 2002).

\section{Enzymes}

\subsection{Historically}

The existence of enzymes has been well-known for over a century. Some of the earliest studies were performed in 1835 by the Swedish chemist Jon Jakob Berzelius who termed their chemical action catalytic. The first isolated enzyme was obtained in a pure form as a result of feat accomplished by James B. Sumner of Cornell University. Sumner was able to isolate and crystallize the enzyme urease from the jack bean. His won the 1947 Nobel Prize for this work. John H. Northrop and Wendell M. Stanley of the Rockefeller Institute for Medical Research shared the 1947 Nobel Prize with Sumner. They discovered a complex procedure for isolating pepsin. This precipitation technique devised by Northrop and Stanley has been used to crystallize several enzymes (Peter, 2015).

\subsection{Chemical Nature of Enzymes}

All known enzymes are protein in nature. They are made up principally of chains of amino acids linked together by peptide bonds whose molecular weights range from 10,000 to 
2,000,000. They can be denatured and precipitated with salts, solvents and other reagents. Many enzymes require the presence of other compounds called cofactors before their catalytic activity can be exerted. This entire active complex is referred to as the holoenzyme of Apo enzyme (protein portion) plus the cofactor. The cofactor compound may be coenzyme, prosthetic group or metal-ion known as activator (Binod, 2013).

$$
\text { Apo enzyme }+ \text { Cofactor }=\text { Holoenzyme }
$$

According to Holum (1968), the cofactor may be:

- Coenzyme: a non-protein organic substance which is dialyzable, thermostable and loosely attached to the protein or Apo enzyme part.

- Prosthetic group: an organic substance which is dialyzable, thermostable and firmly attached to the protein part.

- Activator: a metal-ion which include $\mathrm{K}^{+}, \mathrm{Fe}^{++}, \mathrm{Fe}^{+++}, \mathrm{Cu}^{++}$, $\mathrm{Co}^{++}, \mathrm{Zn}^{++}, \mathrm{Mn}^{++}, \mathrm{Mg}^{++}, \mathrm{Ca}^{++}$, and $\mathrm{Mo}^{+++}$(Figure 1).

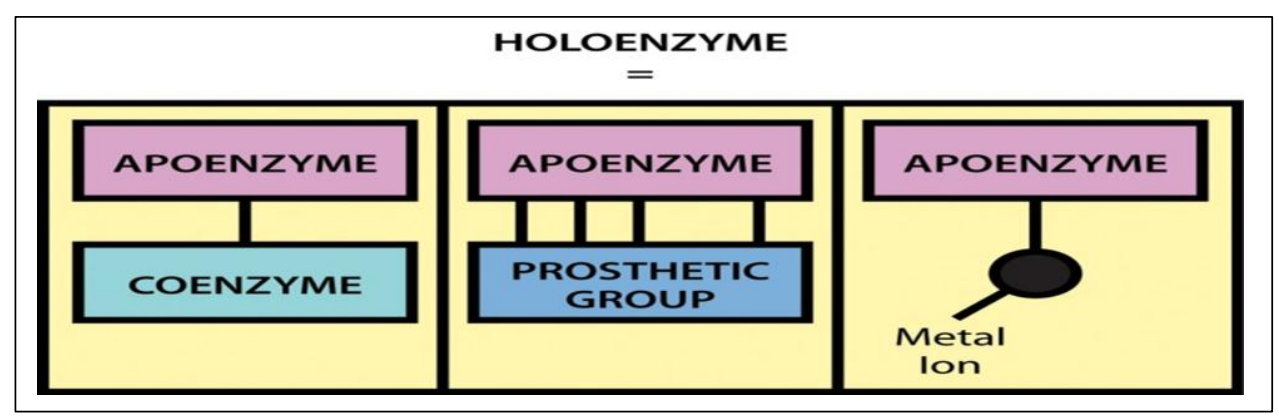

(Figure 1) Holoenzymes consist of Apo enzymes plus various types of cofactors (Peter, 2015) 


\subsection{Specificity of Enzymes}

One of the properties of enzymes that makes them so important as diagnostic and research tools is the specificity they exhibit relative to the reactions they catalyze. A few enzymes exhibit absolute specificity; that is, they will catalyze only one particular reaction. Other enzymes will be specific for a particular type of chemical bond or functional group.

In general, there are four distinct types of specificity:

2.3.1. Absolute specificity: the enzyme will catalyze only one reaction.

2.3.2. Group specificity: the enzyme will act only on molecules that have specific functional groups, such as amino, phosphate and methyl groups (Qiang \& Matrin, 2003).

2.3.3. Linkage specificity: the enzyme will act on a particular type of chemical bond regardless of the rest of the molecular structure.

2.3.4. Stereo chemical specificity: the enzyme will act on a particular steric or optical isomer. Though enzymes exhibit great degrees of specificity. Cofactors may serve many Apo enzymes. For example, nicotinamide adenine dinucleotide (NAD) is a coenzyme for a great number of dehydrogenase reactions in which it acts as a hydrogen acceptor. Among them 
are the alcohol dehydrogenase, malate dehydrogenase and lactate dehydrogenase reactions.

2.3.5. Dual specificity: there are two types of dual specificity.

3.3.5.1. An enzyme acting on 2 different substrates but catalyzes one type of reaction for example, xanthine oxidase acting on hypoxanthine and xanthine causing oxidation of both substrates into uric acid (Binod, 2013).

Hypoxanthine $\rightarrow$ Xanthine $\rightarrow$ Uric acid

3.3.5.2. An enzyme acting on one substrate but catalyzes 2 different reactions for example, isocitric acid dehydrogenase acts on isocitric acid causing dehydrogenation and decarboxylation into $\alpha$ - Ketoglutaric acid.

$$
\begin{gathered}
\text { isocitric acid }+\mathrm{NAD} \rightarrow \mathrm{CO}_{2}+\mathrm{NADH} . \mathrm{H}+\alpha-\text { Ketoglutaric } \\
\text { acid }
\end{gathered}
$$

\subsection{Enzyme Inhibitors}

These are substances which inhibit the enzyme activity. They can be classified into:

\subsubsection{Non-specific Inhibitors}

They are irreversible enzyme poisons which affect all enzymes, such as:

3.4.1.1. All denaturing factors: That for example high temperature, strong acids, strong alkalis, high pressure and ultraviolet ray (Rakesh, 2012). 
3.4.1.2. Sulfhydryl inhibitors: They have high affinity to react with and destroy the $\mathrm{SH}$ group which is present in active sites of all enzymes, these include:

3.4.1.2.1. Heavy metals salts, such as $\mathrm{HgCl}_{2}$, etc...., they form mercaptide with SH.

$$
2 \mathrm{R}-\mathrm{SH}+\mathrm{HgCl}_{2} \rightarrow \mathrm{R}-\mathrm{S}-\mathrm{Hg}-\mathrm{S}-\mathrm{R}+2 \mathrm{HCl}
$$

3.4.1.2.2. Alkylation: Alkylation agents such as Iodoacetic acid can block the SH group by alkylation (formation of alkyl radical).

$$
\mathrm{R}-\mathrm{SH}+\mathrm{ICH}_{2}-\mathrm{COOH} \rightarrow \mathrm{R}-\mathrm{S}-\mathrm{CH}_{2} \mathrm{COOH}+\mathrm{HI}
$$

3.4.1.2.3. Oxidizing agents: Ferricyanide which oxidizes $\mathrm{SH}$ group into a disulfide linkage.

$$
\text { 2R-SH } \rightarrow \text { R-S-S-R }
$$

All these non-specific inhibitors cause irreversible destruction of the enzyme and there is no competition between these nonspecific inhibitors and the substrate for binding to the enzyme. So these non-specific inhibitors cause irreversible and noncompetitive inhibition (Purich, 2010).

\subsubsection{Specific Inhibitors}

They are classified according to the part of the enzyme system they inhibit into:

3.4.2.1. Coenzyme inhibitors: This is specialized in cyanide, hydrazine and hydroxylamine that inhibit pyridoxal phosphate 
(coenzyme form of vitamin B6), and antivitamins such as dicumarol against vitamin $\mathrm{K}$ and sulfanilamide against $\mathrm{p}$-amino benzoic acid (Kabirul, et al., 2013).

3.4.2.2. Inhibitors of specific ion cofactor: This specific Inhibitor such as fluoride inhibits the $\mathrm{Mg}^{2+}$ of enolase enzyme.

3.4.2.3. Prosthetic group inhibitors: This specific Inhibitor such as cyanide inhibits the heme prosthetic group of cytochrome oxidase.

The coenzyme inhibitors, prosthetic group inhibitors and inhibitors of specific ion cofactor cause irreversible and noncompetitive inhibition (Rakesh, 2012).

\subsubsection{Apo enzyme Inhibitors}

3.4.2.4.1. Competitive inhibitors: (Reversible inhibition): The inhibitor has a structural similarity to the substrate. So, the enzyme may bind the substrate or the inhibitor depending on the relative concentration ratio between the inhibitor and substrate (Purich, 2010).

Therefore, enzyme inhibition is reversed by increasing the concentration of substrate over inhibitor, these inhibitors are also called metabolic antagonists.

3.4.2.4.2. Non-competitive inhibitors: They do not compete for the active site with the substrate but do not allow the substrate to bind at the active site. These are actually of two types:

1. Allosteric as shown in first figure BELOW, they bind at different positions but actually cause changes in the active site so new substrate moiety cannot bind (Figure 2) . 
2. In the second figure BELOW the substrate is sterically hindered blocking the active site so the substrate cannot interact with the enzyme (Figure 3) (France, et al., 2000).

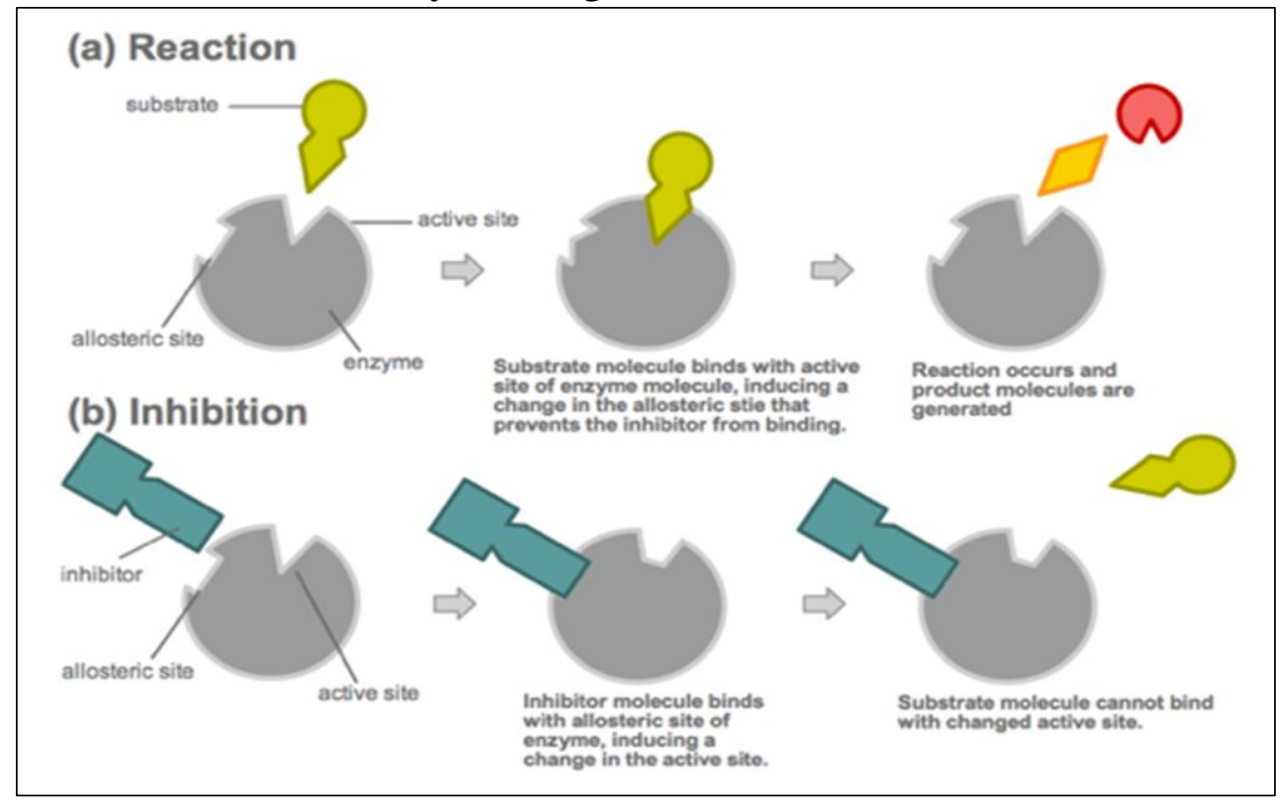

(Figure 2) Non-competitive inhibitors cause changes in the active site. https://commons.wikimedia.org/wiki/File:Allosteric_comp_inhib_2.svg . Sighted in 10 January 2018 at $11.00 \mathrm{am}$. 


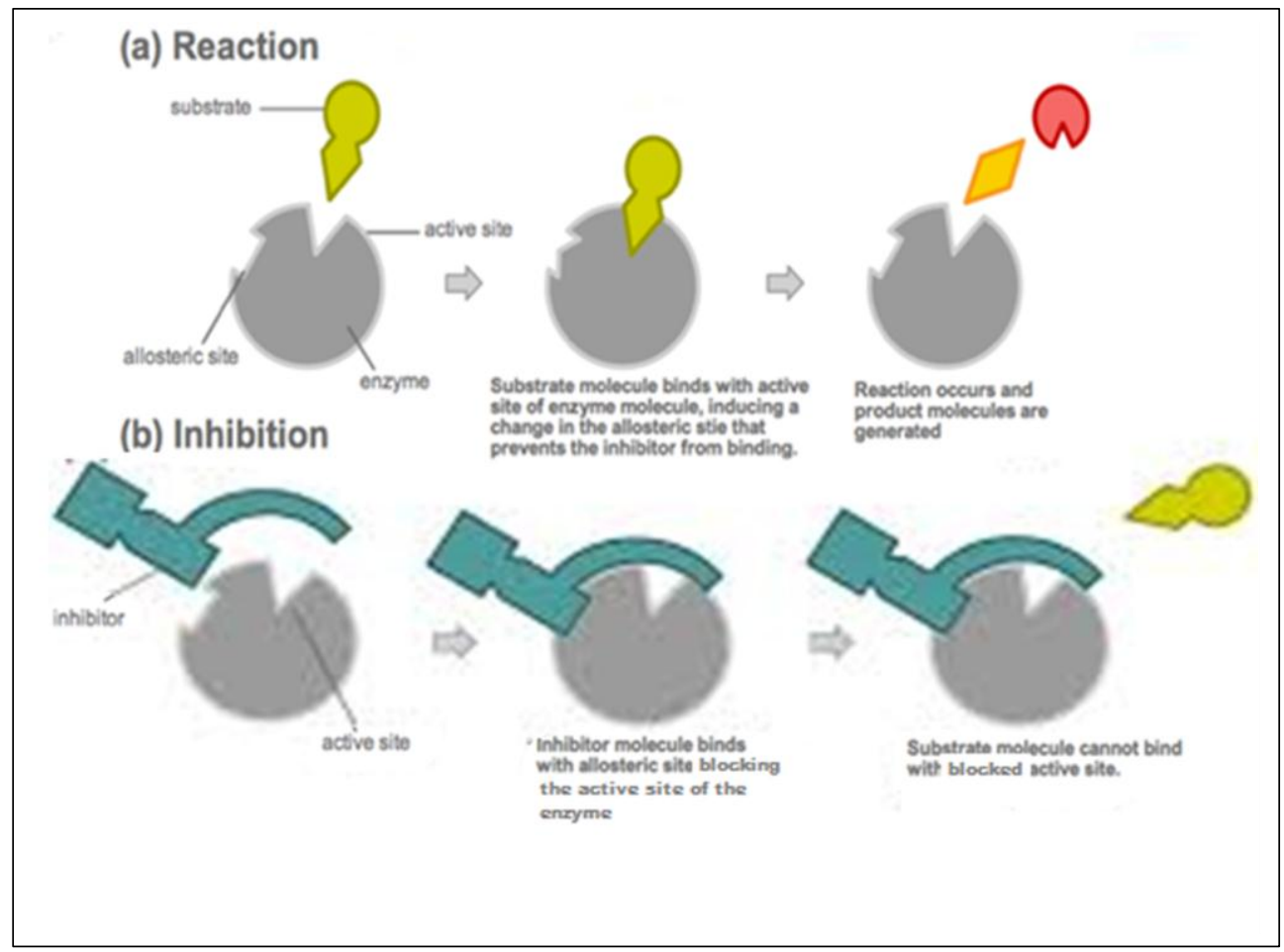

(Figure 3) Non-competitive inhibitors cause sterically hindered blocking the active site.

https://commons.wikimedia.org/wiki/File:Allosteric_comp_inhib_1.svg. Sighted in 10 January 2018 at $1.00 \mathrm{pm}$.

3.4.2.4.2.1. There is no structural similarity between the substrate and inhibitor.

3.4.2.4.2.2. The inhibitor and substrate bind to different or same sites on the enzyme.

3.4.2.4.2.3. The inhibitor bind irreversibly to either free enzyme or the enzyme-substrate complex such as inhibitor does not prevent substrate binding.

3.4.2.4.2.4. Examples of non-competitive inhibitors are the above mentioned nonspecific inhibitors that cause complete 
irreversible inhibition of the enzyme due to modification of its structure (Purich, 2010).

\subsection{The use of enzymes for removing of stains of paper manuscripts and leather artifacts}

Recently, enzymes have been used in the field of restoration of archeological materials in general and specially in paper manuscripts and leather artifacts, because of its nature and components. Enzymes are used for the removal of stains on paper manuscripts and leather artifacts. Larminie (1992) for example, used lipase enzyme in the removal of oil stains from the surfaces of paper manuscripts. This has given satisfactory results. Chandrakant and others (2011) used microbial enzymes to remove air pollutants and anther damage aspects. Jatavathu and others (2011) used protease enzyme in removal of dust and residues resulting from tanning processes. Chandrakant and others (2011) assessed the role of (Lipolase, Celluzyme \& Alcalase) which were used in removing lipid stains. Celluzyme was used to remove Carbohydrate stains such as starch and old adhesives. Alcalase and Pepsin were also used to remove protein stains such as blood and glue stains.

\section{Nano-Catalysis}

\subsection{Nanoparticles}

Nanoparticles (NPs) are particles sized between 1-100 nanometers $\left(10^{-9}\right.$ meters $)$. Synthesis of stabilized nanoparticles sized between 1-100 nm is the main task of the Nano chemistry. Nanoparticles may be synthesized by various categories in two major heads like top-down technologies and bottom-up technologies (Figure 4) (Christian, et al., 2008). 


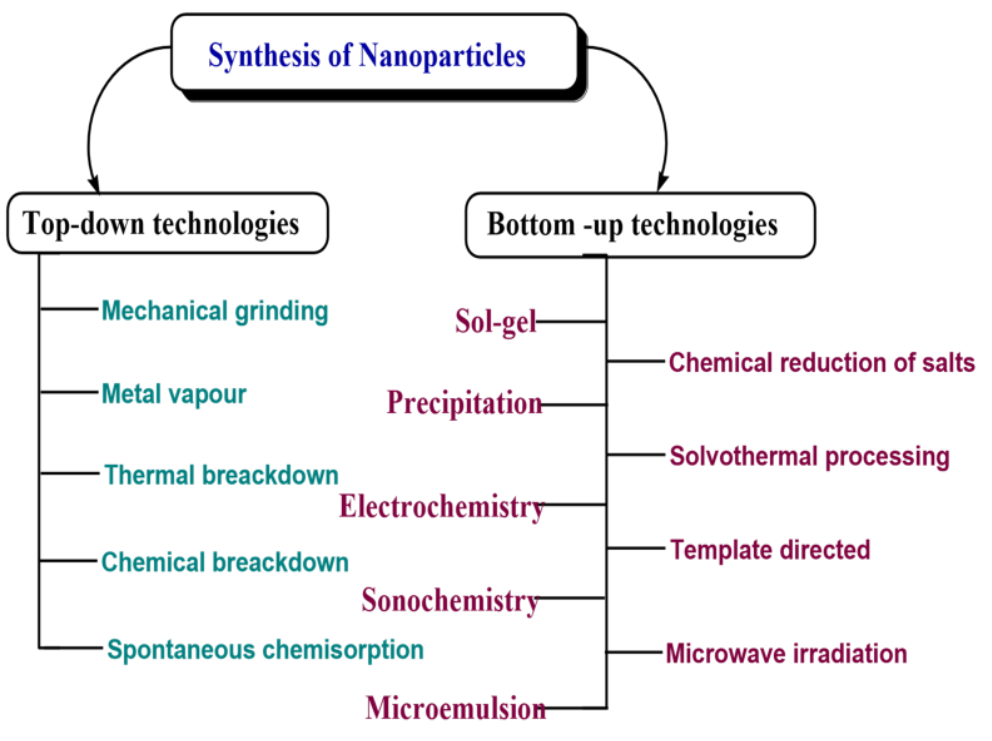

(Figure 4) Various ways to synthesize nanoparticles (Santosh\& Praveen, 2014).

\subsection{Bio-Catalysis}

Bio-Catalysis is one of the pioneer applications of nanoparticles, but appropriate explanation of its tremendous catalytic behavior showing by NPs still has not been fully understood. Large surface area of nanoparticles has a straight forward positive effect on reaction rate and may also be a reasonable explanation of its catalytic activity. Structure and shape-based properties of any materials at its nanoscale size can also affect the catalytic activity of a material (Figure 5) (Tyler, et al., 2006; Boz, et al., 2009; Akia, et al., 2014).

Nano-catalyst can be used in two phase systems (homogeneous and Heterogeneous). Homogeneous system typically means a solution or suspension of nanoparticles in a solvent. However 
in homogeneous Nano-catalysis, the catalyst is in the same phase to the reactants. When designing a Nano-catalyst for use in a solution, it is important to consider how to prevent its aggregation and this is not useful in enzyme catalysis (Santosh \& Praveen, 2014).

Heterogeneous catalysis means that the catalyst is in a different phase to the reactants. It is always considered as more environmentally friendly catalysis due to its high recoverability. The heterogeneous catalyst may be solid or immobilized on a solid inert matrix, and this is not useful in enzyme catalysis. Research to investigate the catalytic potential of various Nano-particle-support systems are such as copper, ruthenium; rhodium, silver, palladium, iron, gold, nickel and platinum nanoparticles (Joseph \& Yurii, 2014).

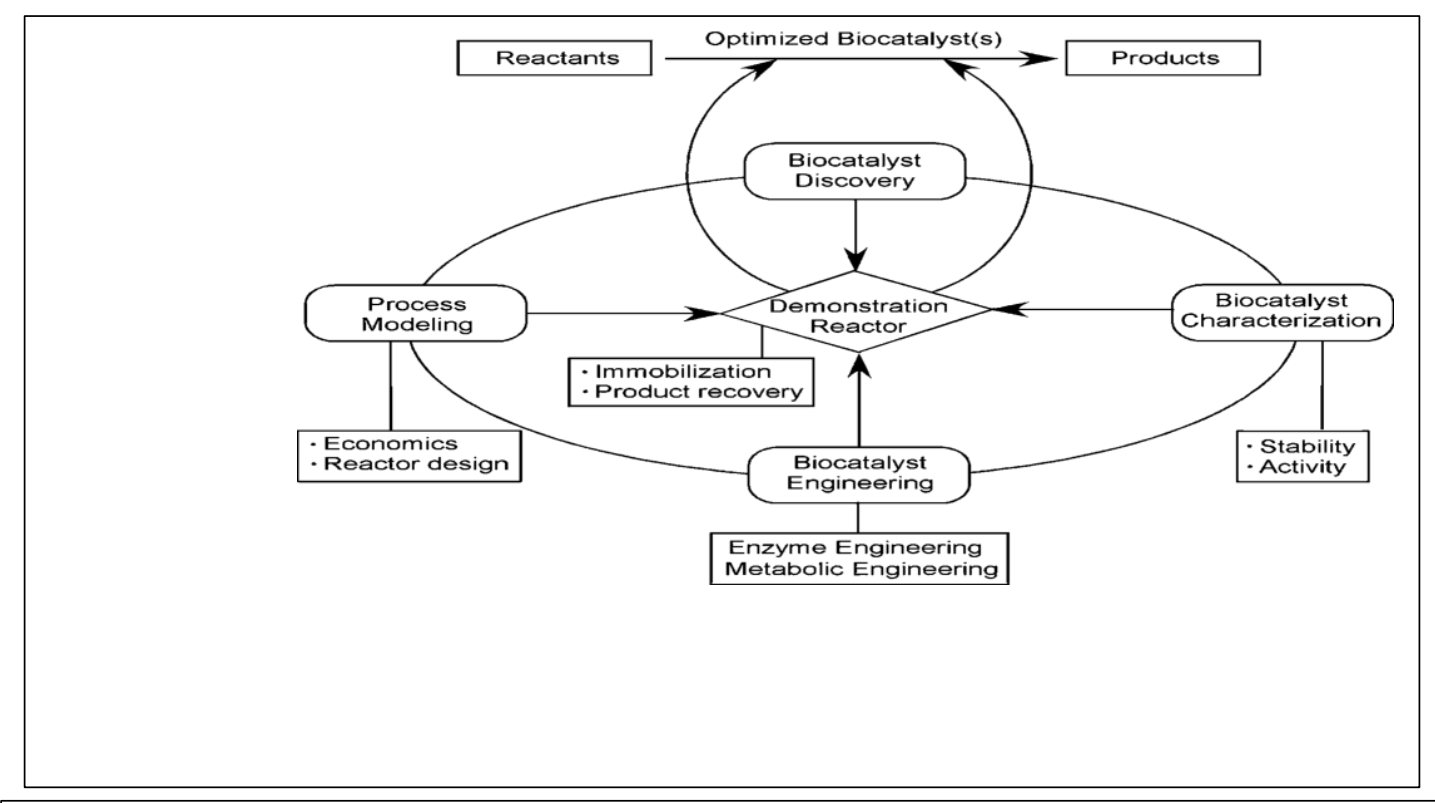

(Figure 5) development of a biocatalytic process (Tyler et al., 2006). 
Due to the large use of enzymes in many applications at present, many studies have been carried out to enhance and improve the efficiency of the enzyme in order to overcome the inhibitors and obstacle of various applications and to develop enzyme structure suitable to many interactions. Several cofactors have been used to improve the efficiency of enzyme such as coenzyme, prosthetic group and activator (Figure 6). In this study metal-ion in the size of nanostructures was used as an activator because it is loosely attached to the protein part in enzyme and easily separates it after the interaction is completed (Cornish-Bowden, 2013).

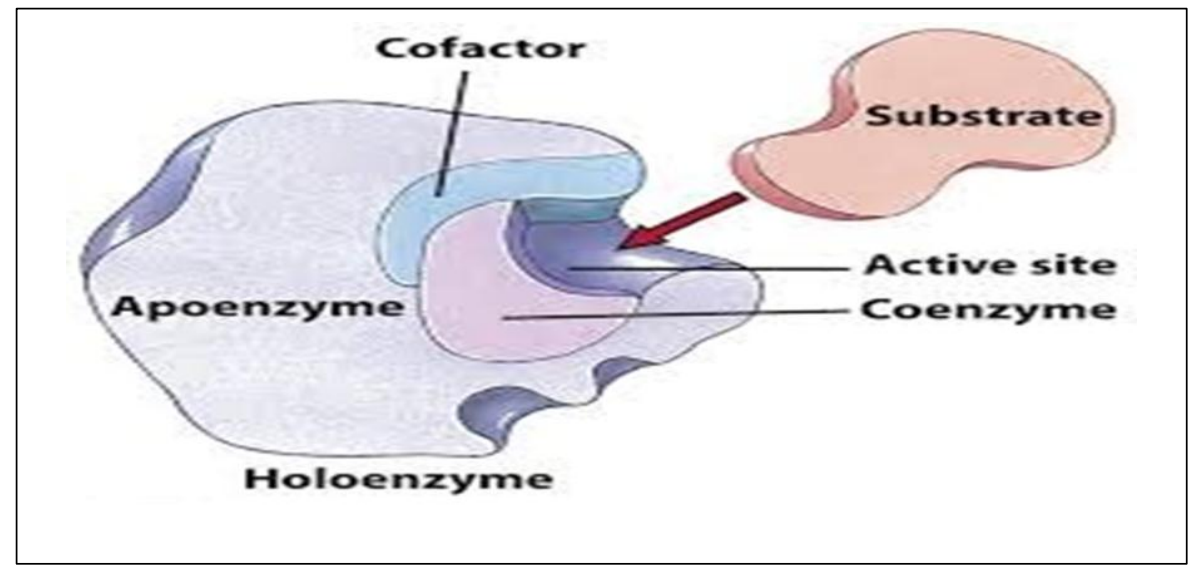

(Figure 6) Role of Co-factor in catalysis enzyme (https://best of biochemistry.wordpress.com/2013/04/10/Cofactors. Sighted in 1 January 2018 at $3.00 \mathrm{pm}$ )

Previous studies on used nanomaterials to catalytic and improve the properties of enzymes were such as Cheng, et al., (2008) who used catalytic nanoparticles to increase the area of the treated surface as well as to increase the permeability of the material, which improves enzyme efficiency. Govan \& Yurii 
(2014) also mentioned the application of nanoparticles to improve the properties of enzymes and consider as support materials in the crystallization of enzymes so that they can be easily applied.

In addition to that, the nanomaterials have many properties which lead to enhance some functions such as: surface photo catalysis (self-cleaning) (Figure 7), antioxidant, antimicrobial surface coatings, consolidation and improvement the physiochemical and mechanical properties (Helmy \& Yasser, 2016; Sierra-Fernandeza, et al., 2017).
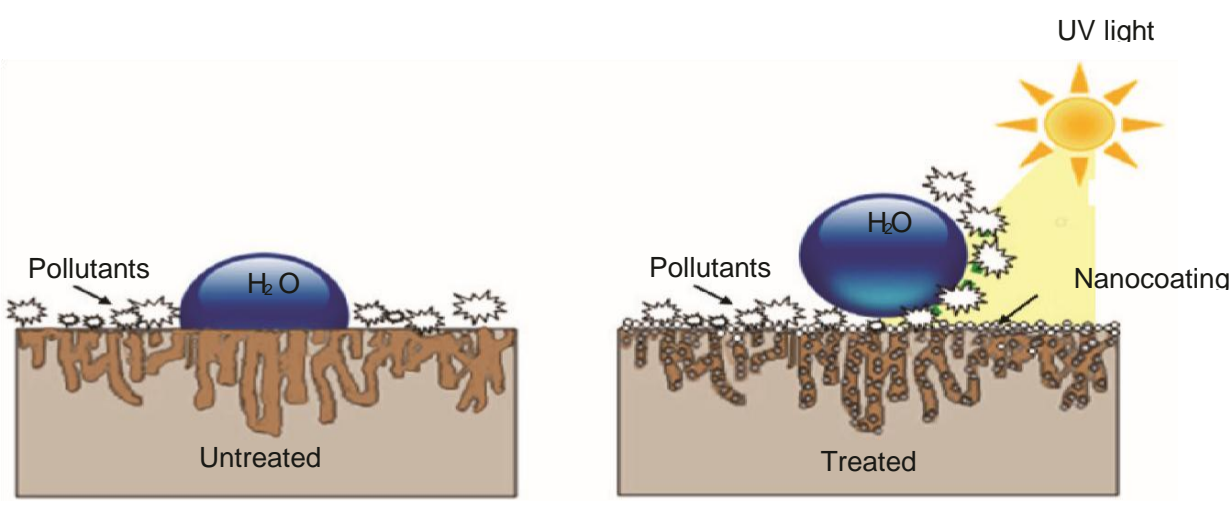

(Figure 7) process photo catalyst for nanoparticles (Sierra-Fernandez et al., 2017)

\subsection{Methods of interconnection of nanoparticle with enzyme}

The interconnection of nanoparticle with enzyme is important to prevent the loss of enzyme activity by not changing the chemical nature or reactive groups in the binding site of enzyme. On the other hand, active site can be protected by the attachment of protective groups, later on which can be removed 
without any loss of enzyme activity. In some cases, this protective function can be fulfilled by a substrate or a competitive inhibitor of the enzyme. The most common procedures of binding nanoparticles with enzyme are adsorption, covalent coupling, entrapment and cross-linking (figure 8) (Razi \& Meryam, 2015).

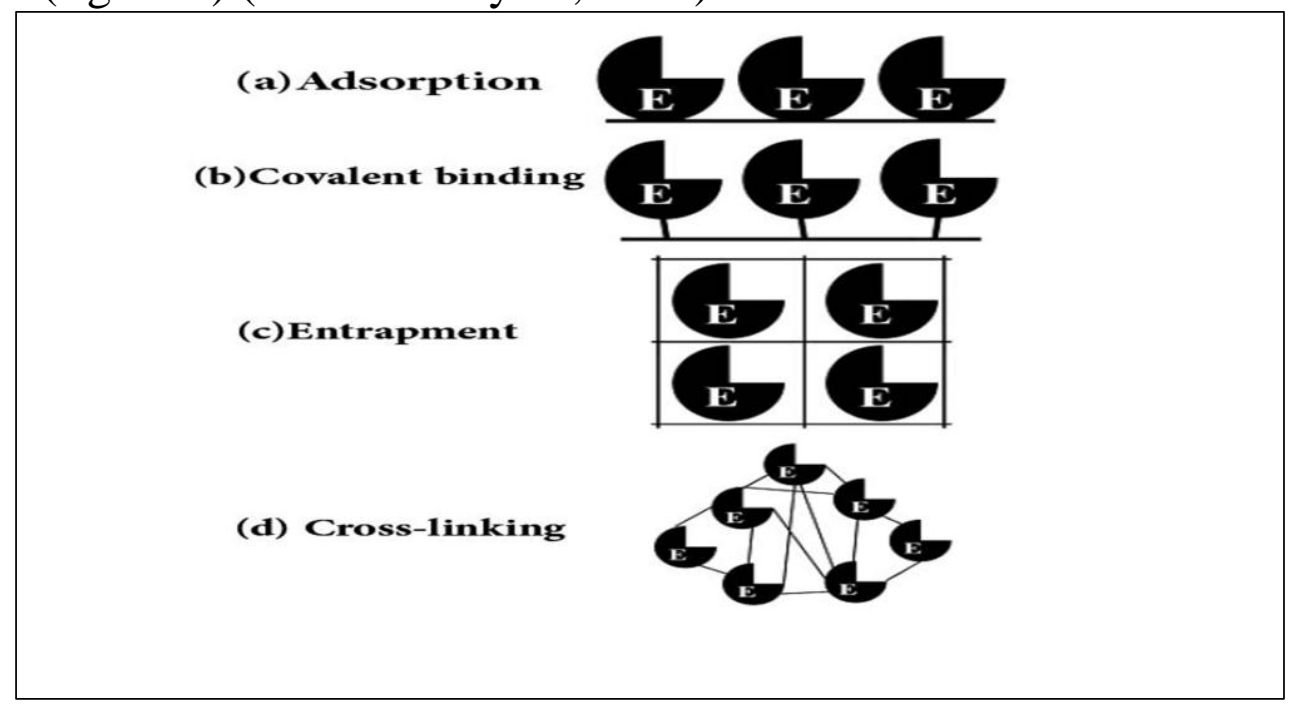

(Figure 8) Methods of interconnection of nanoparticle with enzyme (Razi \& Meryam, 2015).

\subsection{Evaluation of Nano-catalyst Performance Dimensions}

An optimal Nano-catalyst is expected to show superior performance in the following four dimensions:

4.4.1. A selective catalyst produces ideally $100 \%$ of the desired product, even if competing reaction pathways would lead to thermodynamically more stable molecules. Like this, a tedious separation step can be eliminated and the raw material is converted more efficiently to the product without generating unnecessary waste that has to be disposed of. From an 
economical point of view, the process costs can potentially be reduced.

4.4.2. Activity expresses how many molecules of raw material are converted to product molecules by the catalyst per unit of time, the turn over frequency (TOF) is used as a measure for the activity. Conventional homogeneous catalysts display desirably high TOF in the range of $0.3 \mathrm{~s}^{-1}$ or higher, whereas heterogeneous catalysts are in the range of $0.03 \mathrm{~s}^{-1}$ or even lower. Nano catalytic systems are targeted to reach high TOF values as known from their analogous homogeneous systems. Considering industrial applications, high activities are favorable, as a higher output per time can be achieved leading to higher plant capacity utilizations (Yan, et al., 2010).

4.4.3. The lifetime of a catalyst-its durability- is measured by the total number of catalytic cycles it can undergo until it needs to be replaced. A common value used in this context is the turn over number (TON), which denotes the total amount of product (in moles) that can be formed by a given amount (in moles) of catalyst. Therefore, a highly durable catalyst enables the economic production of a larger quantity of the desired compound, before the process has to be interrupted for the replacement of the catalyst (Hagen, 2006).

4.4.4. The major hindrance to the commercial application of a lot of promising homogeneous catalytic systems, successfully tested in the lab, is the recoverability of the catalytically active substance. Therefore, an optimal Nano catalyst features an intrinsic system facilitating its separation from the reaction mixture and its reuse after termination of the reaction. The 
economic advantages are a reduction in needed amounts of expensive catalytic materials and an improvement in product quality, especially with regard to stringent regulations and economic challenges, for example, in the restoration sector. (Sandro, et al., 2014).

\section{Conclusion}

Stains are one of the most deterioration aspects of paper manuscripts and leather artifacts. The improper conditions let to these types of stains. It can be said that these stains are different in its forms and nature. Enzymes are one of the important solutions for removal the problems that caused by stains, but in some cases, enzymes need some catalytic materials that improve their efficiency and increase their activity, as well as reducing their inhibitory response.

Biocatalysis has become an important tool for chemical interactions and gave an effectiveness results. Nanoparticles based on structure size and shape can be used to improve the efficiency and activity of enzymes in order to reduce the inhibitors and problems of applications. The use of nanomaterials to catalysis of enzyme is economically appropriate, because the nanoparticles of a catalyst characterized long lifetime, durability, can be reused after termination of the reaction and needed a little bit amounts of expensive catalytic to improve the product quality. Metal nanoparticles are very promising for greener heterogeneous catalytic reactions, this is appropriate in enzyme catalysis. Nanoparticles can be also used in other purposes with enzyme catalysis such as photo catalytic (self-cleaning) on surface, antioxidant, antimicrobial surface coatings, improvement the physiochemical and mechanical properties, and consolidation. This study referred that the use of nanoparticles will be used 
with enzymes for removal of some stains, and this will be evaluated in another experimental studies.

\section{References}

1- Abdel Kareem, O, (2010): Monitoring, controlling and prevention of the fungal deterioration of textile artifacts in the museum of Jordanian heritage, p95.

2- Akia, M., Yazdani, F., Motaee, E., Han, D., Arandiyan, H. (2014): A review on conversion of biomass to biofuel by nanocatalysts. Biofuel Res J 1:16-25.

3- Berg, J. M., Tymoczko, J. L., Stryer, L., (2002): New York: W H Freeman, Biochemistry. 5th edition.

4- Binod, P., Palkhiwala, P., Gaikaiwari, R., Nampoothiri, K, M., Duggal, A., Dey, K. and Pandey, A. (2013):"Industrial Enzymes-Present status and future perspectives for India," J. Sci. Ind. Res, vol. 72, pp. 271286.

5- Boz, N., Degirmenbasi, N., Kalyon, D. M. (2009): Conversion of biomass to fuel: Transesterification of vegetable oil to biodiesel using KF loaded nano-c-A12O3 as catalyst. Appl Catal B 89:590-596.

6- Chandrakant, S, Karigar \& Shwetha S. Rao (2011): Role ofMicrobial Enzymes in the Bioremediation of Pollutants, Enzyme Research, pp. 2-10.

7- Cheng, Y., Sakai, T., Moroi, R., Nakagawa, M., Sakai, H., Ogata, T.,Terada, Y.(2008): Self-cleaning ability of a photocatalystcontaining denture base material, Dent Mater J, 27(2):pp 179-86.

8- Christian, P., Von der Kammer, F., Baalousha, M., Hofmann,T. (2008): Nanoparticles: structure, properties, preparation and behaviour in environmental media, 
Ecotoxicology, Science+Business Media, LLC, Jul; 17(5):326-43.

9- Cornish-Bowden, A. (2013): Fundamentals of enzyme kinetics: John Wiley \& Sons.

10- Cui, Q. \& karpluus, M. (2003): Catalysis and Specificity in enzyme: A study of triphosphate isomerase and comparison with methyl glyoxal synthase, protein chemistry, vol. 66: pp. 233.

11- Cybulska, M. \& Maik, J. (2007): archaeological textilesaneed for new method of analysis and reconstruction, p187.

12- Helmy, F. M. \& Yasser, K. H. (2016): Using Nanocomposites in the Consolidation and Protection of Sandstone, International Journal of Conservation Science, Volume 7, Issue (1): pp. 29-40.

13- France,Laliberté., Yongxing., Han., Arvind., Govindarajan., André, Giroux., Susana, Liu., Brian, Bobechko., Paula, Lario., Adrienne, Bartlett., Elise, Gorseth., Michael, Gresser., Zheng, Huang. (2000): Conformational difference between PDE4 Apoenzyme and Holoenzyme, Biochemistry, 39 (21): pp 6449-6458.

14- Govan, J., \& Yurii, K. Gun'ko, (2014): Recent Advances in the Application of Magnetic Nanoparticles as a Support for Homogeneous Catalysts, Nanomaterials (4); 222-24.

15- Hagen, J. (2006): Industrial Catalysis: A Practical Approach, Wiley, VCH, Weinheim, Germany, 2nd edition.

16- Holum, J. (1968): Elements of General and Biological Chemistry, 2nd ed., Wiley, NY: 377.

17- Ibrahim, Y,Y, (2014): "Experimental and Applied Studies to Evaluate the Use of Laser Technology in Removal of 
Some Stains from Organic Collective Collectives", Master Thesis, Department of Restoration, Faculty of Archeology, Cairo University, pp. 6-21.

18- Jain, P, S, (2003): applied microbiology microbial degradation of grains, oilseeds, textiles, wood, and corrosion of metals and bioleaching of mineral ores, pp. 26-27.

19- Jatavathu, M., Jatavathu, S., Raghavendra, M, V., Sambasiva K, R, S. (2011): Efficient Leather Dehairing by Bacterial Thermostable Protease, International Journal of Bio-Science and Bio-Technology vol. 3, No.4.

20- Kabirul, Islama., Yuling, Chenb., Hong, Wuc., Ian, R., Bothwella,d., Gil. J., Bluma,d., Hong, Zengc., Aiping, Dongc., Weihong, Zhenga., Jinrong., Minc,E., Haiteng, Dengb., Minkui, Luo. (2013): Defining efficient enzymecofactor pairs for bioorthogonal profiling of protein methylation, University of California, Berkeley, vol. 110, no. 42:pp16778-16783.

21- Larminie, P, (1992): The use of enzymes for the removal of oil stains from paper, In: Conference papers, Manchester (the Institute of Paper Conservation), pp. 119122.

22- Khattab, M, M, A, KH, (2002):"The Effect of Some Industrial Detergents on the Properties of Textile Raw Materials and Consumed Skin", Master Thesis, Department of Home Economics, Faculty of Agriculture, Alexandria University, 2002, p.

23- Nitterus. ( 2000): Fungi in archives and Libraries, Restaurator ISSN, International Journal for the Preservation of Library and archival material, Vol 21, No.1, p.25. 
24- Pedro, F. (2010): Review Article: Enzymes in Food Processing: A Condensed Overview on Strategies for Better Biocatalysts, Hindawi, Enzyme Research, Article ID 862537, p19.

25- Peter, K, R. (2015): Enzymes: principles and biotechnological applications, Essays Biochem. Nov 15; 59: pp. 1-41.

26- Purich, D, L. (2010) Enzyme kinetics: catalysis \& control: a reference of theory and best-practice methods: Elsevier.

27- Rakesh, Sharma. (2012): Enzyme Inhibition and Bio applications, ISBN: 978-953-51-0585-5, In Tech: 1-35.

28- Razi, A. \& Meryam, S. (2015): Enzyme Immobilization: An Overview on Nanoparticles as Immobilization Matrix, Biochemistry \& Analytical Biochemistry, Volume 4, Issue 2: 1000178.

29- Sandro , Olveira., Simon, P., Forster, Stefan, Seeg. (2014): Review Article Nanocatalysis: Academic Discipline and Industrial Realities, Journal of Nanotechnology, ID 324089:19.

30- Santosh, Bahadur, Singh. \& Praveen, Kumar, Tandon. (2014): Catalysis: A Brief Review on Nano-Catalyst, journal of Energy and Chemical Engineering, Vol. 2 Issue. 3:106-115.

31- Sierra-Fernandeza, A., Gomez-Villalbaa, L, S., Rabanalb, M, E., Forta, c, R. (2017): New nanomaterials for applications in conservation and restoration of stony materials: A review, Materials De CONSTRUCCIÓN, Vol. 67, Issue (325): 0465-2746.

32- Tandon, P, K. \& Singh, S, B. (2014): Catalytic applications of copper species in organic transformations: A review, Journal of Catalyst and Catalysis, vol. (1):1-14. 
33- Timar-Balazsy, A. \& Dinah Eastop, D. (1998): Chemical principles of textile conservation" first published, Butter orth, Heinemann, Great Britain, London, pp.157-160.

34- Tyler Johannes., Michael, R., Simurdiak., Huimin, Zhao. (2006): Biocatalysis, Encyclopedia of Chemical Processing, Department of Chemical and Biomolecular Engineering University of Illinois, Urbana, Illinois, U.S.A.

35- Yan, K., Wu, G., Lafleur, T., Jarvis, C. (2014): Production, properties and catalytic hydrogenation of furfural to fuel additives and valueadded chemicals, Renewable and Sustainable Energy Reviews, vol. (38): pp. 663-676.

36- Yan, N., Xiao, C., Kou, Y. (2010): Transition metal nanoparticle catalysis in green solvents: novel and smart materials: design, synthesis, structure, properties and applications. In celebration of the centennial anniversary of chemical research and education at Peking University, Coordination Chemistry Reviews, vol. 254, no. 9-10: pp. 1179-1218.

37- https://bestofbiochemistry.wordpress.com/2013/04/10/cof actors .

38- https://commons.wikimedia.org/wiki/File:Allosteric_com p_inhib_1.svg.

39- https://commons.wikimedia.org/wiki/File:Allosteric_com p_inhib_2.svg. 